\title{
Simulasi Lalu Lintas Akibat Pengembangan Stasiun Jember
}

\section{Traffic Simulation of Jember Railways Station Development}

\author{
Vicky Hidayatullah, Nunung Nuring $\mathrm{H}^{\mathrm{b}}$, Willy Kriswardhana ${ }^{\mathrm{c},}$ \\ ${ }^{a}$ Mahasiswa Jurusan Teknik Sipil, Fakultas Teknik, Universitas Jember, Jl. Kalimantan 37 Jember, email: \\ vicky.hd13@gmail.com \\ b Staf Pengajar Jurusan Teknik Sipil, Fakultas Teknik, Universitas Jember, Jl. Kalimantan 37 Jember, email: \\ nunung.nuring@unej.ac.id \\ ${ }^{\mathrm{c}}$ Staf Pengajar Jurusan Teknik Sipil, Fakultas Teknik, Universitas Jember, Jl. Kalimantan 37 Jember, email: \\ willy.teknik@unej.ac.id
}

\begin{abstract}
ABSTRAK
Jumlah penduduk yang meningkat di Kabupaten Jember menyebabkan kebutuhan akan sarana transportasi di Jember semakin tinggi, khususnya pada transportasi umum jenis kereta api. Peningkatan yang terjadi terlihat dari jumlah penumpang di Daop 9 Jember. Pada tahun 2015 jumlah penumpang kereta api di Stasiun Jember yang semula berjumlah 640.000 penumpang meningkat menjadi 800.000 penumpang pada tahun 2016 (meningkat sekitar 20\%). PT. KAI berencana untuk melakukan pengembangan stasiun Jember agar dapat memberikan kenyamanan dan pelayanan yang lebih baik bagi penumpang kereta api. Pengembangan Stasiun Jember ini akan mengakibatkan perubahan arus lalu lintas di sekitar stasiun, sehingga simulasi-simulasi lalu lintas akibat pengembangan stasiun perlu dilakukan. Simulasi lalu lintas dilakukan dengan membuat skenario arus lalu lintas di sekitar Stasiun Jember, hingga akhirnya dapat diketahui kinerja simpang pada daerah ini. Dalam penelitian ini, metode yang digunakan untuk pengambilan data volume lalu lintas dan inventarisasi yaitu dengan cara survei langsung di lapangan. Pada perhitungan kinerja simpang dan simulasi lalu lintas, metode yang digunakan yaitu metode MKJI (Manual Kapasitas Jalan Indonesia) 1997. Setelah dilakukan analisis, data kinerja simpang yang didapat pada jaringan jalan di sekitar Stasiun Jember sangat beragam. Pada simpang bersinyal, kinerja simpang paling tinggi terdapat pada Simpang SMPN 2 Jember dari kaki simpang timur atau pada Jalan Bedadung dengan tingkat pelayanan (LoS) F. Sedangkan pada simpang tak bersinyal, kinerja simpang tertinggi terdapat pada Simpang Hotel Nusantara dengan tingkat pelayanan (LoS) C. Kemudian, untuk mendapatkan kinerja simpang yang lebih baik di jaringan jalan Stasiun Jember setelah pengembangan, dilakukan manajemen lalu lintas yaitu : pengaturan arus lalu lintas, pemasangan ramburambu lalu lintas pada jaringan jalan, serta pengaturan ulang traffic light pada simpang bersinyal. Setelah dilakukan manajemen lalu lintas tersebut, didapat tingkat pelayanan yang lebih baik pada simpang bersinyal dan simpang tak bersinyal disekitar stasiun Jember, yang berarti skenario lalu lintas yang direkomendasikan layak untuk diterapkan di lapangan.
\end{abstract}

Kata kunci: simulasi lalu lintas, stasiun jember, MKJI 1997

\begin{abstract}
The increasing population in Jember district has caused the higher needs of transportation facilities in Jember, particularly on train as a public transportation. The increase can be seen by the number of passengers in Daop 9 Jember. By 2015, the number of train passengers in Jember Station which originally amounted 640.000 passengers increased to 800.000 passengers by 2016 (increase about 20\%). PT. KAI is planning to develop Jember Station in order to provide convenience and better service for train passengers. Jember Station development will result in changes of traffic flow around the station, so that traffic simulations due to this station development need to be done. Traffic simulations were done by creating scenarios of traffic flow around Jember Station, until the intersection performance of this area can be known.
\end{abstract}


In this study, the method used to collect traffic volume data and inventory is by direct survey on field. In the calculation of intersection performance and traffic simulation, the method used is MKJI (Indonesian Highway Capacity Manual) 1997. After the analysis was conducted, the obtained intersection performance data in road network around Jember Station was very diverse. On signalized intersection, the highest intersection performance was located in SMPN 2 Jember intersection from eastern intersection in Bedadung street with Level of Service (LoS) F. Whereas on unsignalized intersection, the highest intersection performance was located in Hotel Nusantara intersection with Level of Service (LoS) C. Then, in order to obtain a better intersection performance in road network around Jember Station after development, a traffic management was done with : setting the traffic flow, installation of traffic signs on the road network, and also resetting the traffic light in signalized intersection. After the traffic management was conducted, there was a better level of service on both signalized and unsignalized intersection around Jember Station, which means the recommended traffic scenarios are proper to be implemented.

Keywords: traffic simulation, Jember station, MKJI 1997

\section{PENDAHULUAN}

Kabupaten Jember adalah salah satu kabupaten di Provinsi Jawa Timur yang perekonomiannya saat ini sedang meningkat. Peningkatan ini terlihat dari mulai banyaknya dibangun fasilitas dan infrastruktur seperti meningkatnya pembangunan gedung, pariwisata, jaringan telekomunikasi dan transportasi. Semakin tingginya tingkat pertumbuhan perekonomian di Jember membuat pertumbuhan transportasi meningkat, sehingga banyak masyarakat yang memilih untuk menggunakan kendaraan umum seperti kereta api. Peningkatan ini terlihat dari jumlah penumpang kereta api di Daop 9 Jember yang meningkat pesat, pada tahun 2015 jumalah penumpang kereta api di stasiun Jember sebanyak 640.000 penumpang dan pada tahun 2016 meningkat menjadi 800.000 penumpang, atau meningkat sekitar 20\%. Sehingga PT. KAI berencana untuk melakukan pengembangan stasiun Jember agar dapat memberikan kenyamanan dan pelayanan yang lebih baik bagi penumpang kereta api. Pengembangan stasiun Jember ini akan mengakibatkan perubahan arus lalu lintas disekitar stasiun, oleh karena itu perlu dilakukan simulasi-simulasi lalu litas akibat pengembangan stasiun Jember ini. Simulasi ini nantinya akan dibuat skenario-skenario jalannya arus lalu lintas di sekitar stasiun Jember agar dapat mengetahui kinerja ruas maupun simpang setelah dilakukan pengembangan stasiun Jember.

Untuk menentukan simulasi lalu lintas dan menghitung kinerja simpang dapat dilakukan dengan cara manual mengggunakan MKJI 1997 dan menggunakan program komputer seperti KAJI, PTV Vistro, dan lain-lain. perangkat lunak KAJI adalah program komputer dari MKJI 1997 untuk mempermudah analisisnya. Menurut penelitian sebelumnya (Sauri, 2014), terdapat perbedaan antara kinerja yang dihasilkan dengan PTV Vistro dan KAJI, hal ini dikarenakan kedua program ini memiliki angka koreksi dan pendekatan yang berbeda. Untuk itu dalam penelitian ini penulis menggunakan cara MKJI 1997 karena memiliki kesesuaian dengan faktor koreksi dan pendakatan pada model lalu lintas di Indonesia.

\section{METODOLOGI}

Lokasi studi simulasi lalu lintas akibat pengembangan stasiun Jember ini terletak di stasiun Jember Jalan Wijaya Kusuma No. 5 Jember, Jawa Timur 68118, Indonesia dan sekitar Stasiun Jember.

Untuk mengidentifikasi masalah pada penelitian ini dibutuhkan studi literatur yang berkaitan dengan simulasi lalu lintas karena pengembangan stasiun Jember. Studi literatur 
adalah suatu cara yang dipakai untuk mengidentifikasi dan menyelesaikan suatu permasalah dalam penelitian. Studi literatur ini dapat berupa jurnal, buku, dokumentasi, internet dan pustaka.

Metode yang digunakan untuk menganalisis data yaitu menggunakan MKJI (Manual Kapasitas Jalan Indonesia) 1997, setelah data-data dianalisis kemudian diidentifikasi permasalahannya dan dikelompokkan menjadi kelompok permasalahan yang akan diolah dan dianalisis cara menyelesaikan masalahnya yang efektif. Pengelompokan permasalahan tersebut dapat dibagi menjadi perhitungan tingkat pelayanan simpang di sekitar Stasiun Jember, manajemen lalu lintas yang harus dilakukan untuk meningkatkan kinerja simpang pada kondisi mendatang dan penentuan skenario-skenario lalu lintas akibat pengembangan stasiun Jember.

Kriteria perencanaan simulasi lalu lintas akibat pengembangan stasiun Jember ini berpedoman pada pereturan-peraturan tentang jalan yang berlaku di Indonesia unruk wilayah perkotaan. Kriteria tingkat pelayanan yang digunakan untuk menentukan tingkat pelayanan simpang dalam merencanakan skenario lalu lintas untuk rekayasa lalu lintas dapat dilihat pada table 1.

Tabel 1. kriteria tingkat pelayanan simpang untuk simpang bersinyal dan tak bersinyal

\section{Tingkat \\ Pelayanan \\ Tundaan per kendaraan untuk simpang bersinyal (det/kend)}

\begin{tabular}{ccc}
\hline $\begin{array}{c}\text { Tingkat } \\
\text { Pelayanan }\end{array}$ & $\begin{array}{c}\text { Tundaan per kendaraan untuk } \\
\text { simpang bersinyal (det/kend) }\end{array}$ & $\begin{array}{c}\text { Tundaan per kendaraan untuk } \\
\text { simpang tak bersinyal } \\
\text { (det/kend) }\end{array}$ \\
\hline A & $\leq 10$ & $\leq 5$ \\
B & $10-20$ & $5-10$ \\
C & $20-35$ & $11-20$ \\
D & $35-55$ & $21-30$ \\
E & $55-80$ & $31-45$ \\
F & $\geq 80$ & $\geq 45$ \\
\hline
\end{tabular}

Sumber : KM No. 14 Tahun 2006 Tentang Manajemen dan Rekayasa Lalu Lintas

\section{HASIL DAN PEMBAHASAN}

\section{Hasil Survei}

Daerah yang menjadi lokasi studi adalah simpang-simpang yang menghubungkan jalan utama dengan stasiun Jember. Simpang-simpang tersebut merupakan simpang bersinyal dan simpang tak bersinyal.: Letak simpang pada jaringan jalan stasiun Jember dapat dilihat seperti gambar 1 berikut: 


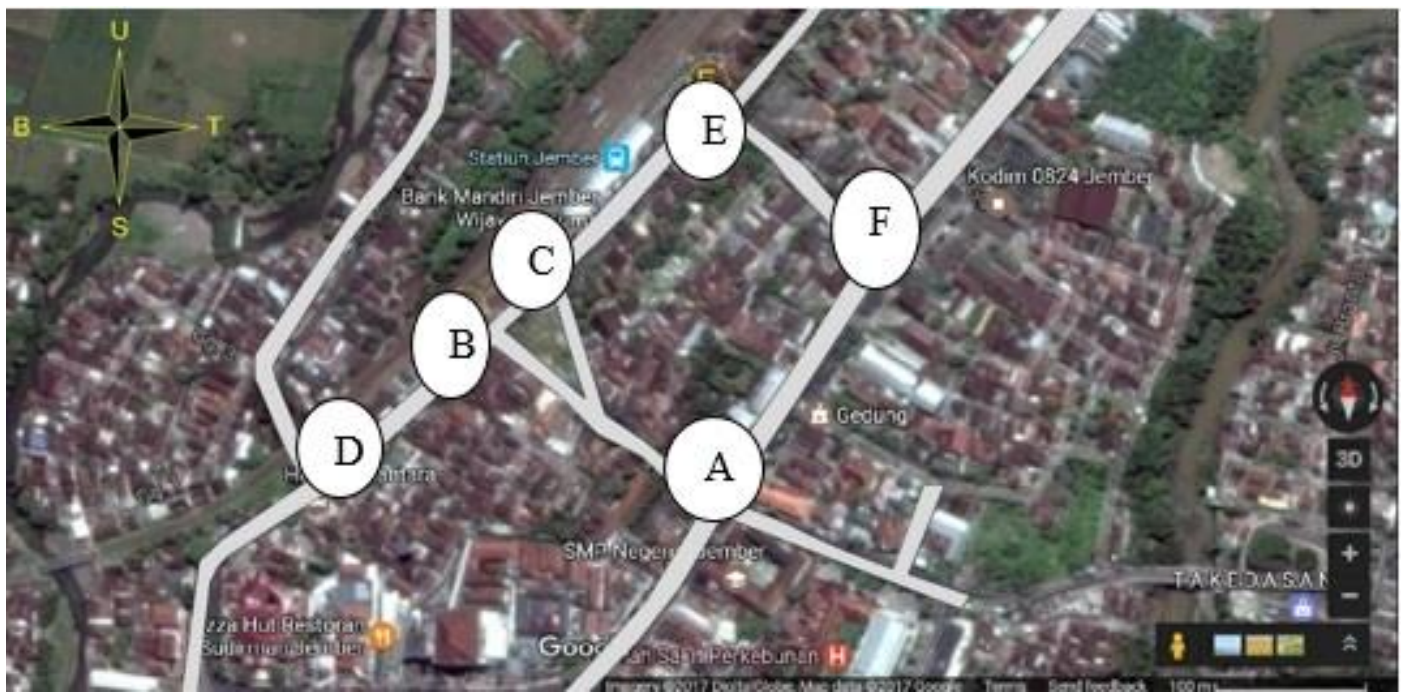

Gambar 1. jaringan jalan stasiun Jember

Pada gambar 1 yaitu jaringan jalan pada Stasiun Jember dengan keterangan sebagai berikut:
A. Simpang SMP 2
B. Simpang pasar bagian selatan
C. Simpang pasar bagian utara
D. Simpang hotel Nusantara
E. Simpang masjid stasiun
F. Simpang keluar stasiun

\section{Perhitungan Kinerja Simpang Pada Kondisi Eksisting Dengan Metode MKJI 1997}

Setelah didapatkan data volume lalu lintas dan inventarisasi simpang selanjutnya dilakukan perhitungan kinerja simpang dengan metode MKJI 1997 menggunakan formulir SIG untuk simpang bersinyal dan formulir USIG untuk simpang tak bersinyal, tujuan dari perhitungan ini yaitu untuk mendapatkan nilai derajat kejenuhan (DS) dan tundaaan dari simpang yang kemudian menjadi acuan untuk menentukan tingkat pelayanan simpang (LOS).

Berikut hasil rekapitulasi derajat kejenuhan (DS), tundaan (D) dan tingkat pelayanan (LOS) pada simpang-simpang di sekitar stasiun jember pada kondisi eksisting yang dihitung dengan menggunakan metode MKJI 1997 pada weekday dan weekend.

Tabel 4. Tingkat pelayanan simpang bersinyal pada weekday dan weekend.

\begin{tabular}{|c|c|c|c|c|c|c|c|c|}
\hline \multirow{2}{*}{$\begin{array}{c}\text { Nama } \\
\text { Simpa } \\
\text { ng }\end{array}$} & \multirow[t]{2}{*}{ Periode } & \multirow[t]{2}{*}{ Kaki Simpang } & \multicolumn{3}{|c|}{ Weekday } & \multicolumn{3}{|c|}{ Weekend } \\
\hline & & & DS & $\begin{array}{c}\text { D } \\
(\operatorname{det} / \mathrm{smp})\end{array}$ & LOS & DS & $\begin{array}{c}\text { D } \\
(\text { det/smp) }\end{array}$ & LOS \\
\hline \multirow[t]{9}{*}{ SMP 2} & Pagi & Pendekat Utara & 1,048 & 165,021 & $\mathrm{~F}$ & 0,980 & 88,381 & $\mathrm{~F}$ \\
\hline & & Pendekat Selatan & 0,704 & 44,413 & D & 0,645 & 47,296 & $\mathrm{D}$ \\
\hline & & Pendekat Timur & 0,804 & 65,601 & $\mathrm{E}$ & 0,986 & 124,584 & $\mathrm{~F}$ \\
\hline & Siang & Pendekat Utara & 1,040 & 152,579 & $\mathrm{~F}$ & 1,094 & 236,570 & $\mathrm{~F}$ \\
\hline & & Pendekat Selatan & 0,634 & 42,567 & $\mathrm{D}$ & 0,710 & 39,440 & $\mathrm{D}$ \\
\hline & & Pendekat Timur & 0,562 & 59,747 & $\mathrm{E}$ & 0,368 & 85,453 & $\mathrm{~F}$ \\
\hline & Sore & Pendekat Utara & 1,102 & 249,761 & $\mathrm{~F}$ & 1,001 & 105,471 & $\mathrm{~F}$ \\
\hline & & Pendekat Selatan & 0,657 & 46,637 & D & 0,594 & 50,550 & D \\
\hline & & Pendekat Timur & 0,386 & 99,802 & $\mathrm{~F}$ & 0,309 & 123,314 & $\mathrm{~F}$ \\
\hline
\end{tabular}


Sumber: Hasil analisis menggunakan metode MKJI 1997

Tabel 5. Tingkat pelayanan simpang tak bersinyal pada weekday dan weekend

\begin{tabular}{|c|c|c|c|c|c|c|c|}
\hline \multirow[t]{2}{*}{ Nama Simpang } & \multirow{2}{*}{$\begin{array}{c}\text { Periode } \\
\text { Jam } \\
\text { Puncak }\end{array}$} & \multicolumn{3}{|c|}{ Weekday } & \multicolumn{3}{|c|}{ Weekend } \\
\hline & & DS & $D(\operatorname{det} / \mathrm{smp})$ & LOS & DS & $D(\operatorname{det} / \mathrm{smp})$ & LOS \\
\hline Stasiun & Pagi & 0.13 & 6,69 & $\mathrm{~B}$ & 0.18 & 6,39 & $\mathrm{~B}$ \\
\hline \multirow[t]{2}{*}{ Selatan } & Siang & 0.10 & 6,35 & B & 0.12 & 5,95 & $\mathrm{~B}$ \\
\hline & Sore & 0.25 & 6,55 & B & 0.12 & 5,77 & B \\
\hline Stasiun & Pagi & 0.20 & 6,46 & B & 0.53 & 9,69 & $\mathrm{~B}$ \\
\hline \multirow[t]{2}{*}{ Utara } & Siang & 0.19 & 6,32 & B & 0.24 & 6,78 & $\mathrm{~B}$ \\
\hline & Sore & 0.26 & 7,06 & B & 0.24 & 6,64 & B \\
\hline \multirow[t]{3}{*}{ Hotel Nusantara } & Pagi & 0.89 & 11,27 & $\mathrm{C}$ & 0.33 & 8,52 & $\mathrm{~B}$ \\
\hline & Siang & 0.78 & 12,96 & $\mathrm{C}$ & 0.49 & 9,73 & $\mathrm{~B}$ \\
\hline & Sore & 0.81 & 13,37 & $\mathrm{C}$ & 0.47 & 9,61 & $\mathrm{~B}$ \\
\hline \multirow[t]{3}{*}{ Masjid Stasiun } & Pagi & 0.11 & 5,35 & B & 0.23 & 6,94 & $\mathrm{~B}$ \\
\hline & Siang & 0.14 & 6,00 & B & 0.22 & 6,45 & $\mathrm{~B}$ \\
\hline & Sore & 0.15 & 5,97 & B & 0.15 & 5,95 & $\mathrm{~B}$ \\
\hline \multirow[t]{3}{*}{ Keluar Stasiun } & Pagi & 0,96 & 17,14 & $\mathrm{C}$ & 0,76 & 12,10 & $\mathrm{C}$ \\
\hline & Siang & 0,67 & 10,72 & $\mathrm{~B}$ & 0,79 & 12,67 & $\mathrm{C}$ \\
\hline & Sore & 0,81 & 13,02 & $\mathrm{C}$ & 0,72 & 11,52 & $\mathrm{C}$ \\
\hline
\end{tabular}

Sumber: Hasil analisis menggunakan metode MKJI 1997

\section{Skenario Arus Lalu Lintas}

Pengembangan stasiun Jember diasumsikan dimulai pada November 2018 dan selesai pada akhir 2019. Pengembangan stasiun Jember ini mengakibatkan jaringan jalan di sekitar Stasiun Jember menjadi berubah dan harus dilakukan pengatturan ulang arus lalu lintas. Untuk membuat simulasi lalu lintas yang baru kita harus terlebih dahulu mengetahui jumlah tarikan dan bangkitan perjalanan yang ditimbulkan akibat perjalanan kereta api dari dan ke stasiun Jember. Pada hari kerja tarikan dan bangkitan perjalanan terbesar terjadi pada jam 15:30 - 16:30 dengan jumlah tarikan dan bangkitan perjalanan sebesar 449 smp/jam, sedangkan pada hari libur tarikan dan bangkitan perjalanan terbesar terjadi pada jam 14:30 - 15:30 dengan jumlah tarikan dan bangkitan perjalanan sebesar $338 \mathrm{smp} / \mathrm{jam}$.

Untuk mengetahui penyebaran arus lalu lintas pada jaringan jalan di sekitar stasiun perlu dilakukan survey asal dan tujuan yang menuju ke stasiun Jember. Data hasil survey asal dan tujuan ini akan dijadikan acuan untuk menyimulasikan pergerakan kendaraan di jaringan jalan di sekitar stasiun Jember. Dari hasil 250 responden penumpang kereta api di stasiun Jember di dapat hasil asal tujuan pada tabel 4.6 dibawah ini:

Tabel 6. Asal dan tujuan

\begin{tabular}{lcc}
\hline \multicolumn{1}{c}{ Asal dan Tujuan } & Jumlah & Persentase (\%) \\
\hline Ajung & 5 & 2 \\
Ambulu & 2 & 0,8 \\
Arjasa & 4 & 1,6 \\
Bangsalsari & 1 & 0,4 \\
Kaliwates & 47 & 18,8 \\
Kebonsari & 2 & 0,8 \\
Mangli & 2 & 0,8 \\
Mumbulsari & 2 & 0,8 \\
Pakusari & 3 & 1,2
\end{tabular}

108 Simulasi Lalu Lintas Akibat Pengembangan Stasiun Jember 


\begin{tabular}{lcc}
\hline \multicolumn{1}{c}{ Asal dan Tujuan } & Jumlah & Persentase (\%) \\
\hline Patrang & 43 & 17,2 \\
Rambipuji & 6 & 2,4 \\
Sukorambi & 1 & 0,4 \\
Sumbersari & 131 & 52,4 \\
\hline \multicolumn{1}{c}{ Jumlah } & $\mathbf{2 5 0}$ & $\mathbf{1 0 0} \%$ \\
\hline
\end{tabular}

Sumber: Survei di lapangan

Setelah di dapat data asal dan tujuan pengendara yang mengakibatkan tarikan dan bangkitan perjalanan pada stasiun jember, dapat di tentukan skenario-skenario arus lalu lintas yang dapat di atur pada jaringan jalan di stasiun Jember setelah dilakukan pengembangan stasiun jember.

Arus lalu lintas pada jaringan jalan si sekitar stasiun jember sebelum dilakukan pengembangan gambar 2.

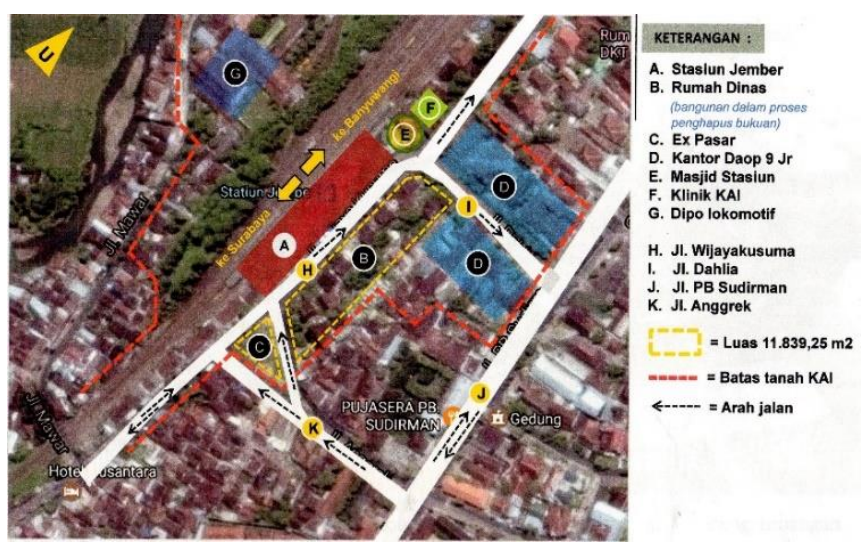
dapat dilihat pada

Gambar 2. Arus lalu lintas pada jaringan jalan di Stasiun Jember kondisi eksisting

Setelah diketahui pengaturan arus lalu lintas saat ini kita juga dapat mengetahui kinerja simpang-simpang pada jaringan jalan di sekitar stasiun Jember sebelum dilakukan pengembangan stasiun. Dari kinera simpang tersebut dapat kita pakai sebagai acuan untuk mengatur ulang arus lalu lintas pada jaringan jalan di sekitar stasiun Jember setelah dilakukan pengembangan stasiun jember. Rekomendasi skenario-skenario pengaturan arus lalu lintas tersebut dapat dilihat pada gambar 3, 4, dan 5 dibawah ini: 


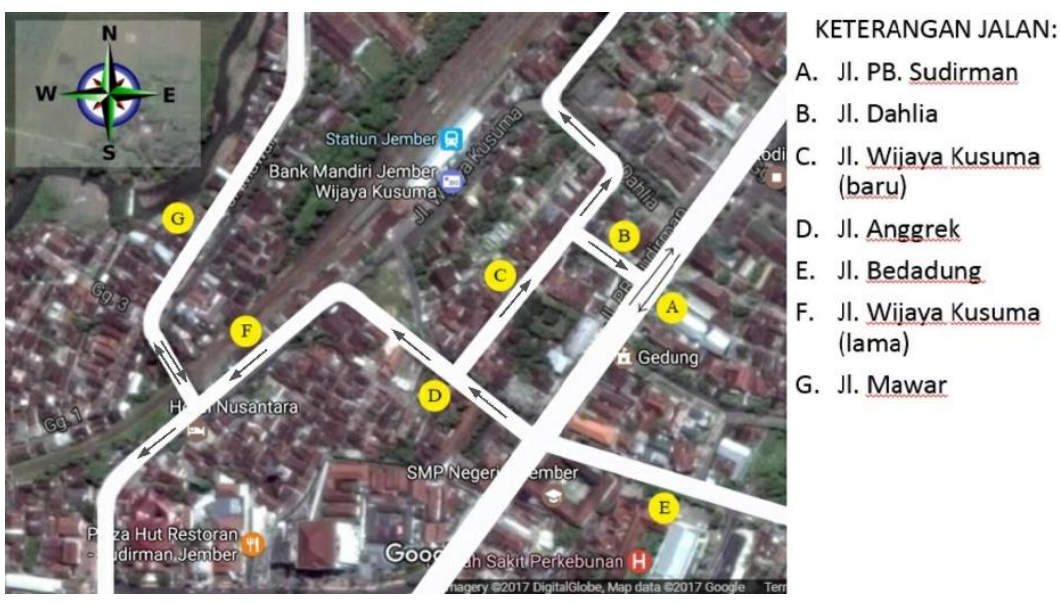

Gambar 3 Skeario ke 1 pengaturan Arus lalu lintas setelah dilakukan pengembangan

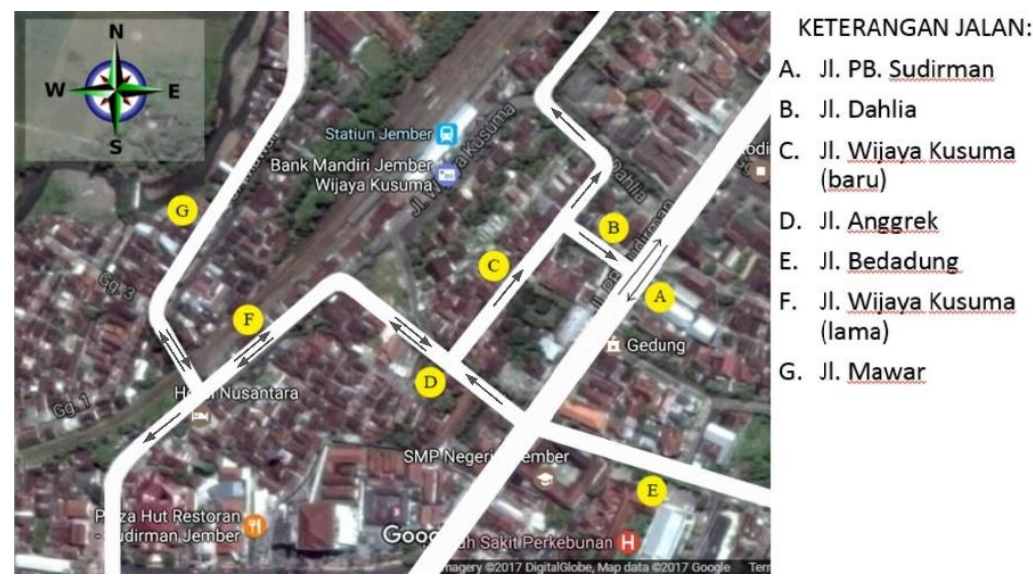

Gambar 4. Skeario 2 pengaturan Arus lalu lintas setelah dilakukan pengembangan

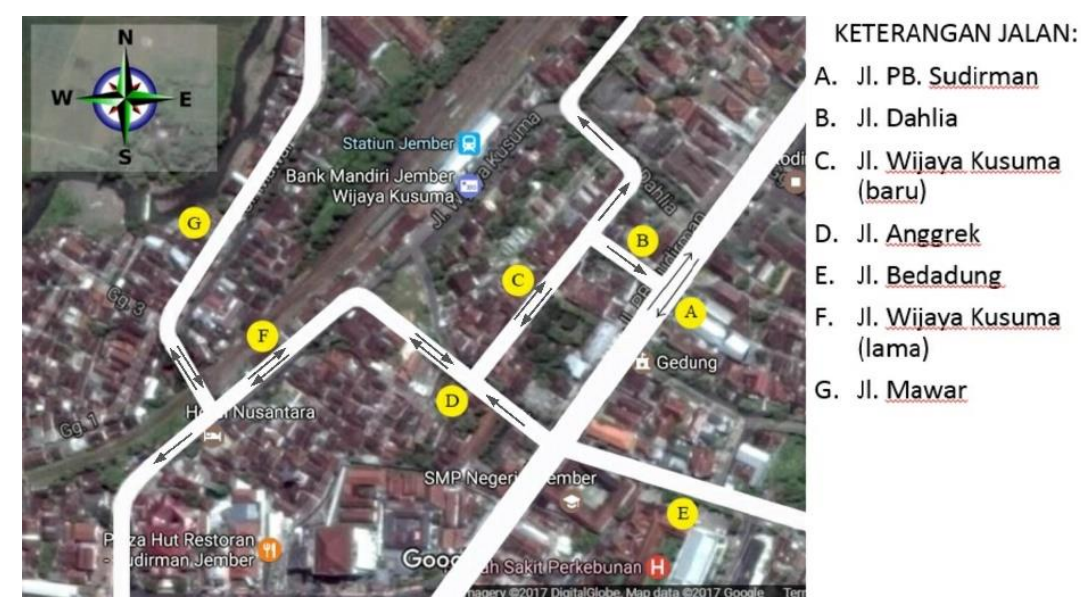

Gambar 5. Skeario 3 pengaturan Arus lalu lintas setelah dilakukan pengembangan

Dari ketiga Skenario simulasi lalu lintas diatas, dilakukan penrhitungan kinerja lalu lintas pada kondisi mendatang setelah dilakukan pengembangan Stasiun Jember menggunakan metode MKJI 1997. Setelah dilakukan perhitungan akan dipilih skenario terbaik berdasarkan kinerja terbaik dari ketiga skenario pengeturan arus lalu lintas diatas. 
Tabel 7 Kinerja Simpang pada kondisi mendatang dengan menggunakan skenario 1 (tahun 2019)

\begin{tabular}{lllcllcccccc}
\hline Nama & Periode & \multicolumn{3}{c}{ Skenario 1 } & \multicolumn{3}{c}{ Skenario 2 } & \multicolumn{3}{c}{ Skenario 3 } \\
\cline { 3 - 10 } & $\begin{array}{c}\text { Jam } \\
\text { Puncak }\end{array}$ & DS & $\begin{array}{c}\text { D (det } \\
\text { /smp) }\end{array}$ & LOS & DS & $\begin{array}{c}\text { D (det } \\
\text { /smp) }\end{array}$ & LOS & DS & $\begin{array}{c}\text { D (det } \\
\text { /smp) }\end{array}$ & LOS \\
\hline Masuk & Pagi & 0,33 & 6,98 & B & 0,36 & 7,44 & B & 0,43 & 8,28 & B \\
Stasiun & Siang & 0,26 & 6,25 & B & 0,27 & 6,62 & B & 0,39 & 8,06 & B \\
& Sore & 0,32 & 7,00 & B & 0,34 & 7,38 & B & 0,44 & 8,53 & B \\
Hotel & Pagi & 0,82 & 13,71 & C & 1,06 & 22,5 & D & 1,06 & 22,5 & D \\
Nusantara & Siang & 0,98 & 18,08 & C & 0,91 & 15,73 & C & 0,91 & 15,73 & C \\
& Sore & 0,87 & 14,74 & C & 0,93 & 16,51 & C & 0,93 & 16,51 & C \\
Simpang & Pagi & 0,18 & 6,23 & B & 0,18 & 6,23 & B & 0,18 & 6,23 & B \\
Jl Dahlia & Siang & 0,22 & 6,91 & B & 0,22 & 6,91 & B & 0,22 & 6,91 & B \\
& Sore & 0,24 & 7,03 & B & 0,24 & 7,03 & B & 0,24 & 7,03 & B \\
Keluar & Pagi & 0,88 & 14,85 & C & 0,88 & 14,85 & C & 0,88 & 14,85 & C \\
Stasiun & Siang & 0,90 & 15,40 & C & 0,90 & 15,40 & C & 0,90 & 15,40 & C \\
& Sore & 0,84 & 13,87 & C & 0,84 & 13,87 & C & 0,84 & 13,87 & C \\
\hline
\end{tabular}

Sumber : Hasil perhitungan menggunakan metode MKJI 1997

\section{Manajemen Lalu Lintas Pada Kondisi Mendatang}

Untuk meningkatkan kinerja jaringan jalan pada Stasiun Jember setelah dilakukan pengembangan ada beberapa manajemen lalu lintas yang dilakukan, yaitu pengaturan arus lalu lintas, pemasangan rambu-rambu lalu intas pada jaringan jalan, serta mengaturan ulang traffic light pada simpang bersinyal.

Dari analisis kinerja simpang pada saat setelah dilakukan pengembangan Stasiun Jember pada tabel 4.16, 4.17, dan 4.18 diatas, penulis merekomendasikan menggunakan skenario 1 untuk diterapkan pada arus lalu lintas mendatang, dikarenakan memiliki kinerja yang lebih baik dari pada skenario 2 dan skenario 3 .

Setelah didapat skenario terbaik pengaturan arus lalu lintas pada jaringan jalan di Stasiun Jember, selanjutnya yaitu pemasangan rambu-rambu lalu lintas untuk memberikan informasi kepada pengguna jalan mengenai lalu lintas di sekitar stasiun jember. Pengaturan rambu-rambu lalu lintas di sekitar Stasiun Jember dapat dilihat pada gambar 4.12 di bawah ini: 


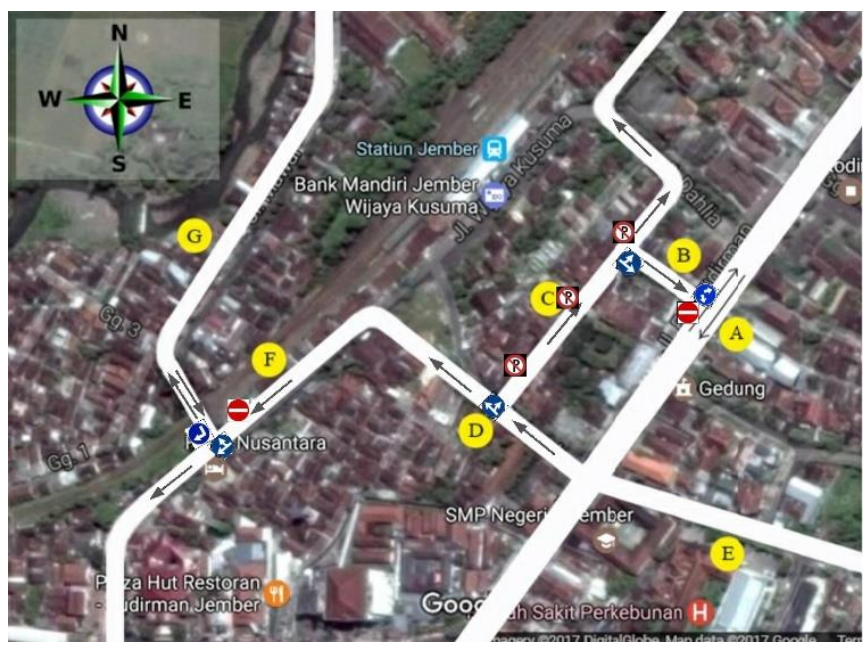

KETERANGAN JALAN:

A. JI. PB. Sudirman

B. JI. Dahlia

C. JI. Wijava Kusuma (baru)

D. Jl. Anggrek

E. Jl. Bedadung

F. JI. Wijava Kusuma

(lama)

G. JI. Mawar

Gambar 6. pengeturan rambu lalu lintas

Untuk meningkatkan kinerja simpang bersinyal dapat dilakukan dengan cara menggatur ulang lampu lalu lintas. Pengaturan ini dapat dilakukan dengan cara mengatur kembali waktu fase sesuai kebutuhan agar kinerja simpang bersinyal menjadi lebih baik. Pengaturan ulang lampu lalu lintas ini dapat dilakukan dengan menggunakan metode MKJI 1997.

Untuk mengatur ulang waktu fase dapat dilakukan dengan menghitung ulang kebutuhan waktu hijau dengan rumus:

$$
\begin{aligned}
& \text { gi }=(\mathrm{Cua}-\mathrm{LTI}) \times \mathrm{PRi} \\
& \text { Dimana: } \\
& \text { gi } \quad=\text { Tampilan waktu hijau pada fase I (det) } \\
& \text { Cua = Waktu siklus sebelum penyesuaian (det) } \\
& \text { LTI = Waktu Hilang Total per Siklus } \\
& \text { PRi }=\text { Rasio Fase }
\end{aligned}
$$

Tabel 8. Redesign traffic light

\begin{tabular}{clcccccc}
\hline \multirow{2}{*}{$\begin{array}{c}\text { Jam } \\
\text { Puncak }\end{array}$} & Lama Waktu & \multicolumn{2}{c}{ Lengan Utara } & \multicolumn{2}{c}{ Lengan Selatan } & \multicolumn{2}{c}{ Lengan Timur } \\
\cline { 3 - 8 } & & $\begin{array}{c}\text { Eksisting } \\
\text { (detik) }\end{array}$ & $\begin{array}{c}\text { Redesain } \\
\text { (detik) }\end{array}$ & $\begin{array}{c}\text { Eksisting } \\
\text { (detik) }\end{array}$ & $\begin{array}{c}\text { Redesain } \\
\text { (detik) }\end{array}$ & $\begin{array}{c}\text { Eksisting } \\
\text { (detik) }\end{array}$ & $\begin{array}{c}\text { Redesain } \\
\text { (detik) }\end{array}$ \\
\hline Pagi & Waktu hijau & 24 & 25 & 34 & 25 & 14 & 18 \\
& Waktu kuning & 2 & 2 & 2 & 2 & 2 & 2 \\
& Waktu Siklus & 90 & 80 & 90 & 58 & 90 & 80 \\
Siang & Waktu hijau & 18 & 17 & 26 & 17 & 13 & 12 \\
& Waktu kuning & 2 & 2 & 2 & 2 & 2 & 2 \\
& Waktu hijau & 75 & 58 & 75 & 58 & 75 & 58 \\
& Waktu hijau & 24 & 25 & 34 & 25 & 14 & 18 \\
& Waktu kuning & 2 & 2 & 2 & 2 & 2 & 2 \\
& Waktu hijau & 90 & 80 & 90 & 80 & 90 & 80 \\
\hline
\end{tabular}

Sumber : Hasil perhitungan menggunakan metode MKJI 1997

Dari hasil pengaturan ulang lampu lalu lintas didapat kinerja simpang SMP 2 setelah pengembangan stasiun Jember dapat dilihat pada tabel 3 dibawah ini: 
Tabel 9. perbandingan Kinerja simpang SMP 2 sebelum setelah pengembangan Stasiun Jember

\begin{tabular}{|c|c|c|c|c|c|c|c|c|}
\hline \multirow[t]{2}{*}{$\begin{array}{c}\text { Nama } \\
\text { Simpang }\end{array}$} & \multirow[t]{2}{*}{$\begin{array}{c}\text { Perio } \\
\text { de }\end{array}$} & \multirow[t]{2}{*}{ Kaki Simpang } & \multicolumn{2}{|c|}{$\begin{array}{c}\text { Eksisting } \\
\text { (tahun 2017) }\end{array}$} & \multicolumn{2}{|c|}{$\begin{array}{c}\text { Tanpa tarikan\& } \\
\text { bangkitan (tahun } \\
\text { 2019) }\end{array}$} & \multicolumn{2}{|c|}{$\begin{array}{c}\text { Dengan } \\
\text { manajemen lalu } \\
\text { lintas (tahun 2019) }\end{array}$} \\
\hline & & & D & LOS & D & LOS & D & LOS \\
\hline \multirow[t]{9}{*}{ SMP 2} & Pagi & PB Sudirman (Utara) & 165,0 & $\mathrm{~F}$ & 320,79 & $\mathrm{~F}$ & 74,97 & $\mathrm{E}$ \\
\hline & & PB Sudirman (Selatan) & 44,41 & $\mathrm{D}$ & 48,653 & $\mathrm{D}$ & 45,39 & $\mathrm{D}$ \\
\hline & & Bedadung (Timur) & 65,60 & E & 353,16 & $\mathrm{~F}$ & 52,15 & $\mathrm{D}$ \\
\hline & Siang & PB Sudirman (Utara) & 152,6 & $\mathrm{~F}$ & 236,57 & $\mathrm{~F}$ & 42,69 & $\mathrm{D}$ \\
\hline & & PB Sudirman (Selatan) & 42,56 & $\mathrm{D}$ & 49,440 & $\mathrm{D}$ & 34,03 & $\mathrm{C}$ \\
\hline & & Bedadung (Timur) & 59,74 & E & 85,453 & $\mathrm{~F}$ & 75,33 & E \\
\hline & Sore & PB Sudirman (Utara) & 249,8 & $\mathrm{~F}$ & 255,47 & $\mathrm{~F}$ & 36,98 & D \\
\hline & & PB Sudirman (Selatan) & 46,64 & D & 50,550 & D & 39,64 & $\mathrm{D}$ \\
\hline & & Bedadung (Timur) & 99,80 & $\mathrm{~F}$ & 123,31 & $\mathrm{~F}$ & 75,14 & E \\
\hline
\end{tabular}

Sumber : Hasil perhitungan menggunakan metode MKJI 1997

\section{KESIMPULAN}

Berdasarkan hasil analisis data dan pembahasan, maka diambil kesimpulan sebagai berikut:

1. Dari hasil analisis kinerja simpang dengan menggunakan metode MKJI 1997 didapat hasil kinerja tertinggi pada simpang bersinyal (simpang SMP 2) yaitu dari arah pendekat utara (Jalan PB. Sudirman) dengan nilai tundaan (D) 249,761 dan Tingkat pelayanan (LOS) F. Pada simpang tak bersinyal hasil kinerja tertinggi terdapat pada simpang keluar stasiun dengan tundaan (D) 17,14 dan tingkat pelayanan (LOS) C.

2. Untuk meningkatkan kinerja simpang pada jaringan jalan di Stasiun Jember dapat dilakukan manajemen lalu lintas seperti : pengaturan arus lalu lintas, pemasangan rambu-rambu lalu intas pada jaringan jalan, serta mengaturan ulang traffic light. Setelah dilakukan manajemen lalu lintas, kinerja jaringan jalan di Stasiun Jember

\section{DAFTAR PUSTAKA}

Anonym. 2004. Undang-undang Nomor 38 Tahun 2004 Tentang Jalan.

Anonym. 2009. Undang-undang Nomor 22 Tahun 2009 Tentang Lalu Lintas.

Anonym. 2015. Peraturan menteri Nomor 22 Tahun 2015.

Arsip PT. KAI Daop 9 Jember

Departemen Pekerjaan Umum. 1997. Manual Kapasitas Jalan Indonesia, MKJI-1997. Indonesia: Departemen PU, Dirjen Bina Marga 
Sauri, Sofyan. 2014. Analisis Kinerja Simpang Menggunakan Perangkat Lunak KAJI dan PTV Vistro (Studi Kasus: Simpang Bersinyal dan Tak Bersinyal Perkotaan Jember). The $17^{\text {th }}$ FSTPT Internatinal Syposium, Jember University, 22-24 August 2014: 1498-1507.

Warpani, S. 1993. Rekayasa Lalu Lintas. Jakarta.

Tamin, Ofyar Z. 2000. Perencanaan dan Pemodelan Transportasi. Edisi kedua. Bandung: Penerbit ITB. 